\title{
Ankle-Brachial Pressure Index and Pulse Wave Velocity as Markers of White Matter Hyperintensities and Cognitive Impairment
}

\author{
Yong S Shim ${ }^{1}$, Bora Yoon ${ }^{2}$, Yun Jeong Hong ${ }^{3}$, A-Hyun Cho ${ }^{1}$, Dong Suk Shim ${ }^{1}$, Hae Eun Shin ${ }^{1}$, Dong Won Yang ${ }^{1^{*}}$ \\ ${ }^{1}$ Department of Neurology, The Catholic University of Korea College of Medicine, 222 Banpo-daero, Seocho-gu, Seoul 137-701, Korea \\ ${ }^{2}$ Department of Neurology, Konyang University College of Medicine, 158 Gwangeodong-ro, Seo-gu, Daejeon 302-718, Korea \\ ${ }^{3}$ Department of Neurology, Yong-In Hyoja Geriatric Hospital, 1-30, Jungbu-daero 874beon-gil, Giheung-gu, Yongin-si, Gyeonggi-do 446-512, Korea
}

*Corresponding author: Dong-Won Yang, Department of Neurology, Seoul St' Mary's Hospital, College of Medicine, The Catholic University of Korea College of Medicine, 222 Banpo-daero, Seocho-gu, Seoul 137-701, Korea, Tel: 82-2-258-6077; Fax: 82-2-599-9686; E-mail: neuroman@catholic.ac.kr

Received date: Aug 03, 2014, Accepted date: Oct 10, 2014, Published date: Oct 15, 2014

Copyright: (C) 2014 Shim YS, et al. This is an open-access article distributed under the terms of the Creative Commons Attribution License, which permits unrestricted use, distribution, and reproduction in any medium, provided the original author and source are credited.

\begin{abstract}
Vascular disease is associated with cognitive impairment. White matter hyperintensities (WMHs), as detected by brain magnetic resonance imaging (MRI), are associated with cognitive impairment and considered to be a marker of cerebral microvascular abnormality. Ankle-brachial pressure index $(\mathrm{ABI})$ and pulse wave velocity $(\mathrm{PWV})$ are noninvasive methods to assess blockage and stiffness in peripheral arteries, respectively. We investigated the associations of $\mathrm{ABI}$ and PWV with WMHs and cognition. We included 242 subjects representing 56 controls, 75 patients with mild cognitive impairment, and 111 patients with Alzheimer's disease. We assessed brachial-ankle PWV (baPWV), ABI, general cognitive status with the Korean Mini-Mental State Examination (K-MMSE), and WMHs with brain MRI. The mean age of subjects correlated with values of baPWV $(r=0.432, p<0.001)$ and ABI $(r=-0.192$, $p=0.002$ ). Among vascular risk factors, baPWV was positively associated with the presence of intracerebral artery stenosis $(r=0.102, p=0.028)$ and $A B I$ was negatively correlated with the presence of hypertension $(r=-0.150$, $p=0.017)$ and smoking $(r=-0.176, p=0.005)$, independent of age. After adjusting for age and vascular risk factors, baPWV was associated with WMHs $(r=0.192, p=0.002)$, and $A B I$ was associated with the K-MMSE score $(r=0.14$, $\mathrm{p}=0.028$ ). There was no association of $\mathrm{ABI}$ with WMHs and of baPWV with K-MMSE. An increased baPWV was associated with the severity of WMHs, and a lower $\mathrm{ABI}$ was associated with cognitive impairment. Management of peripheral vascular disease may help prevent the progression of WMHs or cognitive decline.
\end{abstract}

Keywords: Ankle-brachial pressure index; Pulse wave velocity; Peripheral vascular disease; White matter hyperintensities; Aging; Cognition; Dementia

\section{Introduction}

Cognitive impairment and dementia may result from vascular disease including cerebrovascular disease [1]. In addition to white matter hyperintensities (WMHs), which are markers of cerebral micorvasculopathy, the ankle-brachial pressure index (ABI) and pulse wave velocity (PWV), markers of peripheral arterial disease, are known to be associated with cognitive impairment [2-6]. ABI and PWV are non-invasive measures to assess peripheral arterial health quantitatively, by measuring arterial blockage and stiffness, respectively. $\mathrm{ABI}$ is the ratio of the ankle and the brachial systolic blood pressure and is used to assess the severity of arterial occlusion in the leg. A reduction of ABI suggests the presence of peripheral arterial disease due to atherosclerosis; atherosclerosis in the lower legs represents a similar pathology in other arterial systems $[7,8]$. To assess arterial stiffness, PWV is measured as pressure waves travel a given distance between two sites along the arterial system. Increased arterial stiffness adversely affects the brain, with high pulsatile flow damaging cerebral microvessels, leading progressively to edema, hemorrhage, and inflammation [9].

Similarly, PWV has been reported to be associated with white matter hyperintensities (WMHs) on the brain magnetic resonance imaging (MRI) and other brain structures [10-18]. The etiology of
WMHs may be related to disruption of the blood-brain barrier or leakage of plasma due to cerebral small vessel disease or cerebral microvascular arteriosclerosis [19-23]. Greater WMH volume tends to be associated with poorer cognitive functioning among non-demented older adults [24], and WMH volume among older adults with mild cognitive impairment (MCI) is a risk factor for conversion to Alzheimer's disease [25]. However, the associations of both ABI and $\mathrm{PWV}$, with WMHs and cognitive impairment, are not yet clear.

Several mechanisms may explain the cognitive associations of ABI and PWV. First, arterial stiffness often damages pressure pulsatility, resulting in hemodynamic stress in the brain. The high levels of central pulse pressure in the brain result in dysfunction to its microcirculation $[26,27]$. Moreover, high pulse pressures may result in structural changes to cerebral blood vessels, which in turn may interfere with the transport of important nutrients to the brain and interfere with the clearance of toxic byproducts out of the brain [28]. Second, atherosclerosis may induce cerebral hypoperfusion leading to cerebral hypoxia. These conditions may destabilize neurons and synapses, generating a neurodegenerative process characterized by formation of senile plaques, neurofibrillary tangles, and amyloid angiography $[29,30]$.

We presently evaluated the association of WMHs, markers of cerebral microvasculopathy, with peripheral artery disease, as indicated by ABI and brachial-ankle PWV (baPWV). Additionally, we analyzed the association of $\mathrm{ABI}$ and baPWV with cognitive impairment, as assessed with a brief neuropsychological measure. We hypothesized that both ABI and baPWV would be associated with 
WMHs, and thereby cognitive impairment as well. A strategy based on analyses of surrogate markers, such as $\mathrm{ABI}$ and $\mathrm{PWV}$, may result in a targeted and effective prevention of WMHs and cognitive impairment.

\section{Materials and Methods}

\section{Subjects}

This was a single-center observational study approved by the Institutional Review Board of The Catholic University of Korea, Bucheon St. Mary's Hospital. Subjects provided informed consent. Between May 2011 and December 2012, we consecutively enrolled patients who visited the hospital's Department of Neurology clinic. A total of 242 subjects were recruited, including 56 controls, 75 patients with $\mathrm{MCI}$, and 111 patients with $\mathrm{AD}$. Healthy adults who requested a medical evaluation for a routine assessment of possible cerebrovascular diseases, due to concerns related to stroke or positive vascular risk factors, were enrolled as controls. Control subjects had no cognitive complaints and their scores on the Korean version of MMSE (K-MMSE) [31] were above -1.0 standard deviations compared with age- and education-matched norms, and their clinical dementia rating (CDR) [32] scores were zero. Patients with MCI fulfilled the clinical diagnostic criteria for MCI [33]. Criteria from the National Institute of Neurologic and Communicative Disorders as well as the Stroke and the Alzheimer Disease and Related Disorders Association [34] were used to diagnose patients with probable AD.

All subjects underwent physical and neurological examinations, blood tests (i.e., complete blood count, blood chemistry, vitamin B12/ folate, syphilis serology), thyroid function tests, assessment of global cognitive functioning with the K-MMSE, MRI and MR angiography (MRA) of the brain, and measurements of ABI and baPWV. The height and weight of subjects were measured, and body mass index (BMI) was calculated. Subjects' history of vascular risk factors (i.e., hypertension, diabetes, hyperlipidemia, ischemic heart disease, stroke, and smoking) was recorded. Subjects were excluded from the study if there were large territorial infarcts on MRI, were younger than 55 years of age, had a history of diseases (other than MCI or AD) that may cause cognitive disorder, or had major psychiatric disease.

\section{MRI assessment}

All patients had 1.5T brain MRI (Intera; Philips Medical Systems, Best, The Netherlands), including fluid-attenuated inversion recovery (FLAIR) imaging and T1/T2-weighted imaging. The slice thickness was $5 \mathrm{~mm}$ without an interslice gap. The imaging protocol for MRA was the three-dimensional time-of-flight method. The periventricular WMHs (PVHs) and the deep WMHs (DWHs) were separately evaluated, as proposed by the Clinical Research for Dementia Of South Korea (CREDOS) [35]. The severity of DWHs was rated according to their largest diameter, with the categories D1 $(<10 \mathrm{~mm}), \mathrm{D} 2(\geq 10$ and $<25 \mathrm{~mm}$ ), and D3 ( $\geq 25 \mathrm{~mm}$ ). The PVHs were rated as P1 if the cap and band were $<5 \mathrm{~mm}, \mathrm{P} 2$ if the cap or band was $\geq 5$ and $<10 \mathrm{~mm}$, and P3 if the cap or band was $\geq 10 \mathrm{~mm}$.

With modification from prior criteria [36], we added Grade 0 (absence; D0 or P0) in the individual ratings of PVHs and DWHs, and the severity of total WMHs was reclassified into none (Grade 0), minimal (Grade 1), moderate (Grade 2), and severe (Grade 3) [35]. Table 1 presents modified CREDOS ratings of WMHs for all subjects.

\section{ABI and baPWV measurements}

The ABI and the baPWV were measured by an oscillometric device (form PWV/ABI, COLIN, Tokyo, Japan). In addition to recording the limb lead echocardiogram, mechano-cardiograms were simultaneously recorded by attaching blood pressure cuffs with a tonometic sensor to the upper arm and ankle. The ABI was determined as the ratio of ankle systolic blood pressure to brachial systolic blood pressure. To calculate the ABI, brachial pressure and ankle pressure were measured on both the left and right limbs with subjects in the supine position. The high ankle pressure method was used. After checking the systolic pressures in the dorsalis pedis and posterior tibial arteries of both the legs, the higher of these two ankle pressures for each leg is then divided by the higher brachial systolic pressure [37].

\begin{tabular}{|c|c|c|c|c|}
\hline & $\begin{array}{l}\mathrm{D}^{0} \\
\text { (none) }\end{array}$ & $\begin{array}{l}\mathrm{D}^{1} \\
(<10 \mathrm{~mm})\end{array}$ & $\begin{array}{l}D^{2} \\
(10-24 \\
\mathrm{mm})\end{array}$ & $\begin{array}{l}D^{3} \\
(>25 \mathrm{~mm})\end{array}$ \\
\hline PO (none) & $\begin{array}{l}\text { None } \\
(n=26)\end{array}$ & $\begin{array}{l}\text { Minimal } \\
(\mathrm{n}=10)\end{array}$ & & \\
\hline $\begin{array}{l}\text { P1 (capping/banding, both } \\
<5 \mathrm{~mm} \text { ) }\end{array}$ & $\begin{array}{l}\text { Minimal } \\
(n=35)\end{array}$ & $\begin{array}{l}\text { Minimal } \\
(\mathrm{n}=32)\end{array}$ & $\begin{array}{l}\text { Moderate } \\
(\mathrm{n}=2)\end{array}$ & \\
\hline $\mathrm{P} 2$ (in between) & $\begin{array}{l}\text { Minimal } \\
(\mathrm{n}=5)\end{array}$ & $\begin{array}{l}\text { Minimal } \\
(\mathrm{n}=49)\end{array}$ & $\begin{array}{l}\text { Moderate } \\
(\mathrm{n}=17)\end{array}$ & $\begin{array}{l}\text { Moderate } \\
(\mathrm{n}=2)\end{array}$ \\
\hline $\begin{array}{l}\text { P3 (either capping/banding } \\
\geq 10 \mathrm{~mm} \text { ) }\end{array}$ & & $\begin{array}{l}\text { Moderate } \\
(\mathrm{n}=23)\end{array}$ & $\begin{array}{l}\text { Moderate } \\
(\mathrm{n}=28)\end{array}$ & $\begin{array}{l}\text { Severe } \\
(n=13)\end{array}$ \\
\hline
\end{tabular}

Table 1: Ratings of the white matter hyperintensities modified from CREDOS The periventricular hyperintensities and the deep white matter hyperintensities were separately evaluated and the results were combined to give a representative rating of the WMH as 'minimal, moderate' and 'severe'. CREDOS, Clinical Research for Dementia of South Korea; D, rating of the deep white matter hyperintensities; P, rating of the periventicular hyperintensities.

The baPWV was calculated by time-phase analysis. The time interval between the wave front of the brachial waveform and that of the ankle waveform was defined as the time interval between the brachium and ankle ( $\Delta \mathrm{Tba})$. The distance between sampling points of baPWV was calculated automatically according to the height of the subject. The path length from the suprasternal notch to the brachium (Lb) was obtained from superficial measurements and was expressed using the following equation: $\mathrm{Lb}=0.2195 \times$ height of the patient (in $\mathrm{cm})-2.0734$. The path length from the suprasternal notch to the ankle (La) was obtained from superficial measurements and was expressed using the following equation: $\mathrm{La}=(0.8129 \times$ height of the patient (in $\mathrm{cm})+12.328$ ). Finally, the following equation was used to obtain baPWV: baPWV $=(\mathrm{La}-\mathrm{Lb}) / \Delta \mathrm{Tba}[38]$. The ABI and baPWV from both right and left limbs were recorded.

\section{Cognitive and neurological measures}

K-MMSE: The K-MMSE [31] is the Korean modification and translation of the mini mental state examination (MMSE) [39]. The MMSE is a frequently used instrument to assess global cognitive functioning and to identify individuals with cognitive impairment. 
Citation: Shim YS, Yoon B, Hong YJ, Cho AH, Shim DS, et al. (2014) Ankle-Brachial Pressure Index and Pulse Wave Velocity as Markers of White Matter Hyperintensities and Cognitive Impairment. J Neurol Neurophysiol 5: 239. doi:10.4172/2155-9562.1000239

Page 3 of 7

Consistent with the MMSE, the K-MMSE scores range from 0-30, with lower scores indicating greater cognitive impairment.

Clinical Dementia Rating (CDR): The CDR [32,40] is a 5-point rating scale used to indicate the presence and level of severity of $\mathrm{AD}$. Individuals' score on the CDR is based on ratings of their cognitive and functional performance in six domains, memory, orientation, community affairs, judgment and problem solving, personal care, home and hobbies, as assessed during a structured-interview [40]. Each of these domains is rated on the following 5-point scale 0 (no impairment), 0.5 (questionable impairment, 1 (mild impairment), 2 (moderate impairment) to 3 (severe impairment), with the exception of personal care, which is rated on a 4 point scale (with no rating of .5) [40]. Scores from each of these domains are combined with an algorithm to create a composite CDR [40]. This composite, or global $\mathrm{CDR}$, falls into the following categories: 0 (no dementia), .5 (questionable), 1 (mild dementia), 2 (moderate dementia), and 3 (severe dementia) [40]. The CDR also generates Sum of Boxes score, which is calculated by summing each of the six domain scores, with scores ranging from 0 to 18 (higher scores indicating greater impairment).

Hachinski Ischemic Score (HIS): The HIS [41] is a brief tool to help differentiate vascular dementia from AD. It consists of 13 items, each representing a feature believed to be associated with vascular dementia [42]. Items are rated as either a one or a two, and are summed to create a total score [42]. Diagnostic differentiation is based on specific cut-off scores, with a score equal to or less than four suggesting $\mathrm{AD}$ and a score of seven points or more suggesting vascular dementia (total scores equaling five or six were later considered to be a mixed form) [42]. Because this study included patients with $\mathrm{AD}$, not vascular dementia, for the analyses we used just total scores for evaluating the vascular risks of subjects, without consideration of the cut-off scores for diagnostic differentiation.

\section{Statistical analyses}

Preliminary analyses examined differences between three subject groups (controls, $\mathrm{AD}$, and $\mathrm{MCI}$ ) on demographic characteristics, $\mathrm{BMI}$, and medical history, with analysis of variance (ANOVA) and chisquare analyses (where appropriate). Group differences were further examined for cognitive and neurological measures' scores, WMH severity levels, baPWV, and ABI with analysis of covariance (ANCOVA) and chi-square test, adjusting for age and years of education. The Scheffé method was used for testing multiple comparisons across the three subject groups. Partial correlations were used to examine associations among the key variables, baPWV, ABI, WMH ratings, and the K-MMSE score, while controlling for age and vascular risk factors, among the total sample. This correlation analysis was further repeated for each of the three subject groups. The right and left $A B I$ and baPWV were averaged and then entered in to the correlation analysis. A probability value of $\mathrm{p}<0.05$ was considered statistically significant, and all tests were 2-tailed. The data were analyzed with SPSS 15.0 (SPSS, Chicago, IL, USA)

\section{Results}

\section{Characteristics of the subjects}

A total of 242 subjects were included in this study. The majority of subjects were female $(72.73 \%, \mathrm{n}=176$ subjects). The mean age of subjects significantly differed across the three subject groups, with the control group being the youngest in age and the $\mathrm{AD}$ group being the oldest. Subjects with AD had significantly lower years of education than subjects with MCI and controls. After adjusting for age and years of education, K-MMSE score, CDRs, and WMH ratings significantly differed across the three subject groups. There were no group differences for the Hachinski ischemic scale, BMI, or vascular risk factors. After adjusting for age, ABI values, but not baPWV values, significantly differed across the three groups. Table 2 presents means, standard deviations, ANOVA, ANCOVA, and chi-square results.

\begin{tabular}{|c|c|c|c|c|c|}
\hline & Control $(n=56)$ & $\mathrm{MCl}(\mathrm{n}=75)$ & $A D(n=111)$ & $p$ value & $\begin{array}{l}\text { Multiple } \\
\text { comparison } \\
(p<.05)\end{array}$ \\
\hline Age (years) & $66.46 \pm 6.59$ & $70.01 \pm 8.09$ & $75.63 \pm 5.84$ & $<0.001$ & $\begin{array}{l}A D \text { vs. } \mathrm{MCl} \text { vs. } \\
\text { Control }\end{array}$ \\
\hline Sex (male:female) & $17: 39$ & $22: 53$ & $27: 84$ & 0.633 & \\
\hline Education (years) & $10.19 \pm 4.12$ & $6.55 \pm 4.60$ & $4.95 \pm 4.76$ & $<0.001$ & $\begin{array}{l}A D \text { vs. } \mathrm{MCl} \text {, } \\
\text { Control }\end{array}$ \\
\hline K-MMSE & $28.07 \pm 1.53$ & $22.89 \pm 3.38$ & $15.83 \pm 5.23$ & $<0.001 \dagger$ & $\begin{array}{l}\text { AD vs. } \mathrm{MCl} \text { vs. } \\
\text { Control }\end{array}$ \\
\hline CDR & $0.13 \pm 0.22(0 \sim 0.5)$ & $0.48 \pm 0.10(0 \sim 0.5)$ & $1.25 \pm 0.84(0.5 \sim 3)$ & $<0.001 \dagger$ & $\begin{array}{l}\text { AD vs. } \mathrm{MCl} \text { vs. } \\
\text { Control }\end{array}$ \\
\hline $\mathrm{SOB}$ & $0.28 \pm 0.41(0 \sim 1.5)$ & $1.75 \pm 0.93(0.5 \sim 5)$ & $7.02 \pm 4.69(0.5 \sim 18)$ & $<0.001 \dagger$ & $\begin{array}{l}\text { AD vs. } \mathrm{MCl} \text {, } \\
\text { Control }\end{array}$ \\
\hline HIS & $1.50 \pm 1.31(0 \sim 4)$ & $1.92 \pm 1.73(0 \sim 7)$ & $2.51 \pm 2.24(0 \sim 10)$ & 0.294 & \\
\hline BMI & $23.30 \pm 2.68$ & $23.53 \pm 2.92$ & $22.98 \pm 3.27$ & 0.471 & \\
\hline
\end{tabular}


Citation: Shim YS, Yoon B, Hong YJ, Cho AH, Shim DS, et al. (2014) Ankle-Brachial Pressure Index and Pulse Wave Velocity as Markers of White Matter Hyperintensities and Cognitive Impairment. J Neurol Neurophysiol 5: 239. doi:10.4172/2155-9562.1000239

Page 4 of 7

\begin{tabular}{|c|c|c|c|c|c|}
\hline \multicolumn{6}{|l|}{ History of } \\
\hline Hypertension & $24(42.86 \%)$ & $40(53.33 \%)$ & 64 (57.66\%) & 0.331 & \\
\hline Diabetes mellitus & $9(16.07 \%)$ & $17(22.67 \%)$ & 32 (28.83\%) & 0.292 & \\
\hline Hyperlipidemia & $9(16.07 \%)$ & $10(13.33 \%)$ & $18(16.22 \%)$ & 0.842 & \\
\hline $\begin{array}{l}\text { Ischemic } \\
\text { heart disease }\end{array}$ & $5(8.93 \%)$ & $7(9.33 \%)$ & $10(9.01 \%)$ & 0.988 & \\
\hline Stroke & $1(1.79 \%)$ & $5(6.67 \%)$ & $12(10.81 \%)$ & 0.138 & \\
\hline Smoking & $3(5.36 \%)$ & $5(6.67 \%)$ & $10(9.01 \%)$ & 0.761 & \\
\hline $\begin{array}{l}\text { Intracerebral } \\
\text { artery stenosis }\end{array}$ & $11(19.64 \%)$ & $35(46.67 \%)$ & $74(66.67 \%)$ & 0.006 & $\begin{array}{l}\mathrm{AD}, \quad \mathrm{MCl} \text { vs. } \\
\text { Control }\end{array}$ \\
\hline Rating of WMHs & $0.95 \pm 0.56(0 \sim 2)$ & $1.11 \pm 0.72(0 \sim 3)$ & $1.59 \pm 0.68(0 \sim 3)$ & 0.001 & $\begin{array}{l}\text { AD vs. } \mathrm{MCl} \text {, } \\
\text { Control }\end{array}$ \\
\hline PVHs & $1.18 \pm 0.86(0 \sim 3)$ & $1.45 \pm 1.07(0 \sim 3)$ & $2.08 \pm 0.89(0 \sim 3)$ & 0.006 & $\begin{array}{l}A D \text { vs. } \mathrm{MCl} \text {, } \\
\text { Control }\end{array}$ \\
\hline DWMHs & $0.73 \pm 0.62(0 \sim 2)$ & $0.82 \pm 0.75(0 \sim 3)$ & $1.36 \pm 0.89(0 \sim 3)$ & 0.004 & $\begin{array}{l}A D \text { vs. } \mathrm{MCl} \text {, } \\
\text { Control }\end{array}$ \\
\hline R_baPWV (sec/cm3) & $1667.70 \pm 422.97$ & $1670.89 \pm 352.76$ & $1891.98 \pm 447.25$ & $0.248^{*}$ & \\
\hline L_baPWV (sec/cm3) & $1676.38 \pm 377.53$ & $1693.25 \pm 367.04$ & $1896.21 \pm 437.83$ & $0.367^{*}$ & \\
\hline R_ABI & $1.14 \pm 0.06$ & $1.13 \pm 0.10$ & $1.08 \pm 0.10$ & 0.010 & $\begin{array}{l}A D \text { vs. } \mathrm{MCl} \text {, } \\
\text { Control }\end{array}$ \\
\hline L_ABI & $1.15 \pm 0.06$ & $1.13 \pm 0.10$ & $1.10 \pm 0.11$ & 0.012 & AD vs. Control \\
\hline
\end{tabular}

Table 2: Clinical characteristics of the subjects; Values are presented as mean \pm standard deviation (range) or number and percentage. Comparisons among three groups by using the analysis of covariance and chi-square test, where appropriate. Age and teducation years were adjusted for the analyses. ${ }^{*}$ Differences of baPWV values were significant before adjusting for age (all, $\left.\mathrm{p}<0.001\right)$. MCI, mild cognitive impairment; $\mathrm{AD}$, Alzheimer's disease; MMSE, mini-mental state examination; CDR, clinical dementia rating; SOB, sum of boxes; HIS, Hachinski ischemic scale; BMI, body mass index; PVHs, periventricular hyperintensities; DWMHs, deep white matter hyperintensities; baPWV, brachial-ankle pulse wave velocity; ABI, ankle-brachial pressure index; R, right side; L, left side.

\begin{tabular}{|c|c|c|c|c|}
\hline & WMHst & K-MMSE† & Age & Vascular risk factors ${ }^{*}$ \\
\hline \multirow[t]{3}{*}{ baPWV } & $r=0.192$ & $r=-0.009$ & $r=0.432$ & (ICA stenosis) \\
\hline & $p=0.002$ & $\mathrm{P}=0.447$ & $p<0.001$ & \\
\hline & $\begin{array}{l}(\mathrm{PVHs}) r=0.207, p=0.001 \\
(\mathrm{DWMHs}) r=0.129, p=0.044\end{array}$ & & & \\
\hline \multirow[t]{4}{*}{ ABI } & $r=0.036$ & $r=0.111$ & $r=-0.192$ & (HTN) \\
\hline & $\mathrm{P}=0.586$ & $\mathrm{p}=0.044$ & $p=0.002$ & \\
\hline & & & & (Smoking) \\
\hline & & & & (ICA stenosis) \\
\hline
\end{tabular}

Table 3: Correlation analysis of baPWV and ABI with WMHs and MMSE, adjusted for age and vascular risk factors ( $\mathrm{n}=242$ ); The analyses were adjusted for *age or †age and vascular risk factors. baPWV, brachial-ankle pulse wave velocity; ABI, ankle-brachial pressure index; WMHs, white matter hyperintensities; MMSE, mini-mental state examination; ICA, intracerebral artery; HTN, hypertension.

\section{Association of ABI and baPWV with WMHs and K-MMSE}

Table 3 presents partial correlations among the study's key variables, $\mathrm{ABI}$, baPWV, WMH ratings, and K-MMSE total score, after adjusting for age or both age and vascular risk factors. Both baPWV and $\mathrm{ABI}$ were significantly correlated with age, with the correlations being negative and positive, respectively. Among the vascular risk 
Citation: Shim YS, Yoon B, Hong YJ, Cho AH, Shim DS, et al. (2014) Ankle-Brachial Pressure Index and Pulse Wave Velocity as Markers of White Matter Hyperintensities and Cognitive Impairment. J Neurol Neurophysiol 5: 239. doi:10.4172/2155-9562.1000239

Page 5 of 7

factors, baPWV was positively associated with the presence of intracerebral artery stenosis and ABI was negatively associated with the presence of hypertension and smoking, after adjusting for age.

After adjusting for age and vascular risk factors, baPWV was positively associated with both PVHs and DWHs, in addition to WMHs. However, ABI did not differ according to the severity of WMHs (Figure 1).

A significant positive association between general cognitive status and peripheral arterial health was observed, specifically between the KMMSE total score and ABI. A similar association was not observed for baPWV. The K-MMSE score was negatively associated with WMH severity (Figure 1). Among patients with $\mathrm{AD}$, the K-MMSE was significantly associated with $\mathrm{ABI}(\mathrm{r}=0.214, \mathrm{p}=0.028)$ and WMHs were significantly associated with baPWV $(\mathrm{r}=0.261, \mathrm{p}=0.007)$. Correlations among the key variables, $\mathrm{ABI}$, baPWV, WMH ratings, and K-MMSE total score, were not statistically significant within the control and MCI groups.

\section{Discussion}

Early detection of stroke risk factors may contribute to stroke reduction and prevention of vascular-related cognitive decline. Routine brain MRI screening for vascular risk factors, within neurologically asymptomatic older adults, is costly and not economical for primary use. Measurements of the ABI and PWV provide one of the most practical, and relatively cost-effective tools to objectively assess the presence of atherosclerosis and arterial stiffness. Several previous studies $[2,5,43]$ suggested that, even at subclinical levels, atherosclerosis and arterial stiffness are associated with an increased risk of progressive cognitive decline and that $\mathrm{ABI}$ and PWV might be of clinical value in identifying older people who are at increased risk of cognitive impairment and stroke.

This study demonstrated that ABI and baPWV, clinical markers of peripheral artery disease, were associated with neurocognitive aging. Findings indicated that $\mathrm{ABI}$ and baPWV were associated with vascular risk factors. ABI was significantly associated with intracerebral artery stenosis; baPWV was significantly associated with hypertension, smoking, and intracerebral artery stenosis. In terms of the study's key variables, $\mathrm{ABI}$ was associated with cognitive impairment and baPWV was correlated with WMHs, independent of age and vascular risk factors. Thus, the hypothesis that both ABI and baPWV would be associated with cognitive function and $\mathrm{WMH}$ ratings was partially supported.

Arterial stiffness has been previously demonstrated as an independent predictor of cardiovascular disease events and risk factors $[44,45]$, which in turn are important predictors of cognitive decline. The relationship between WMHs and baPWV has also been reported. Increased baPWV has been significantly associated with WMHs in multivariate analyses [12-14,17], consistent with our study. This result supports the arteriosclerotic etiology of WMHs because an increased baPWV indicates progression of arteriosclerotic change. Prior findings have also shown null statistical findings regarding the association between $\mathrm{ABI}$ and WMHs [4,17], as was also shown in the present study. ABI might not be sufficient to predict WMHs, which result from various factors including demyelination as well as cerebrovascular disease $[19,21,23]$.

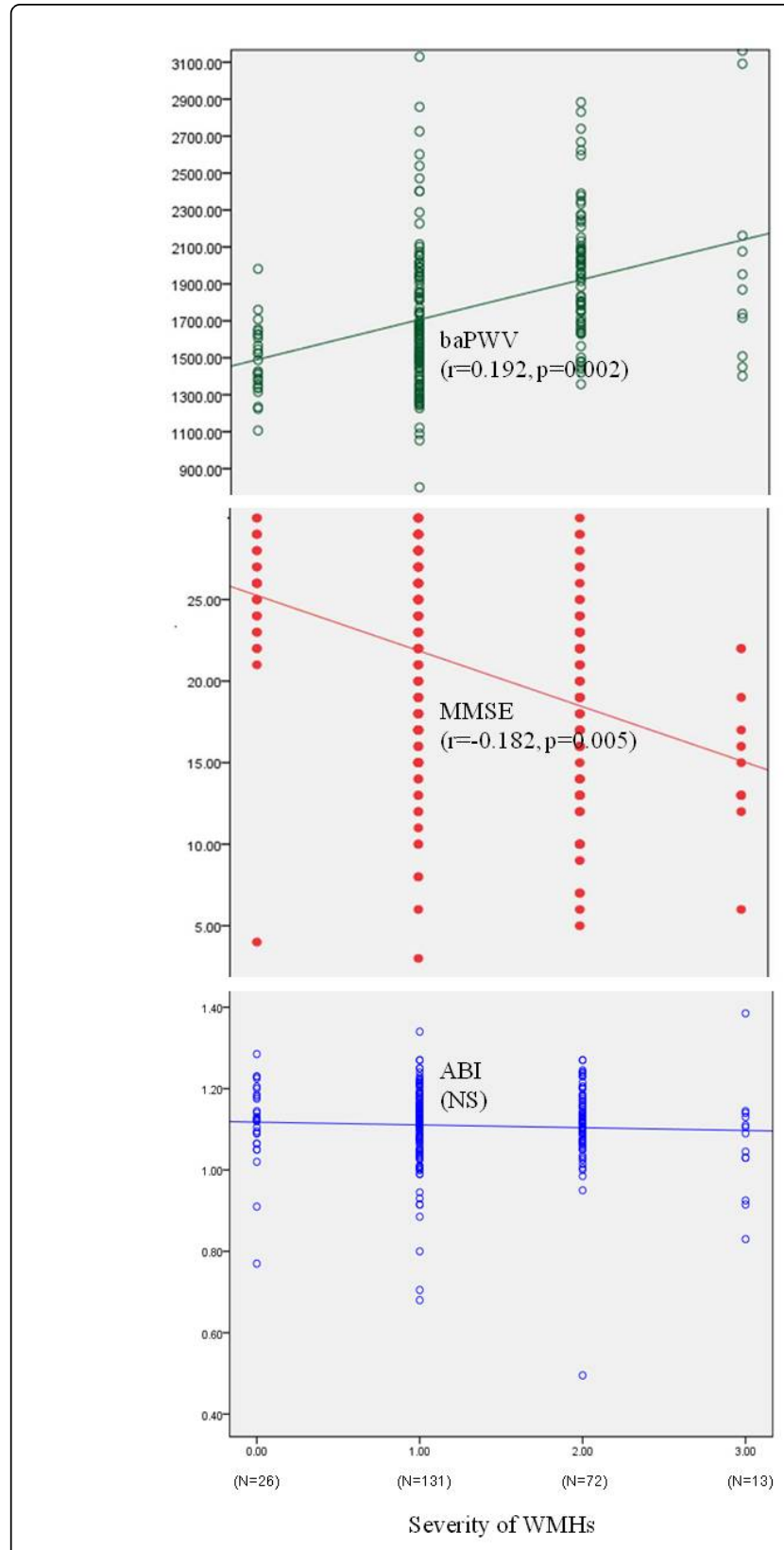

Figure 1: Correlation analyses of ABI, baPWV, and MMSE with the severity of WMHs. Age and vascular risk factors were adjusted for the analyses. ABI, ankle-brachial pressure index; baPWV, brachialankle pulse wave velocity; MMSE, mini-mental state examination; WMHs, white matter hyperintensities.

Null findings regarding the association of baPWV and global cognitive functioning may be a result of the PWV measurement site. Non-significant associations between baPWV and cognitive impairment have been previously reported [6,46-48]. However, a number of studies [48-51] used carotid-femoral PWV (cfPWV) and found inverse relationships between cfPWV and MMSE. In contrast to cfPWV, the association between baPWV and cognitive function is less known $[6,48]$. Although baPWV tends to be associated with cfPWV $[38,52]$ and cfPWV is the main determinant of baPWV [52], there is a 
substantial difference between the two techniques over the range of measurement [53]. The baPWV is affected by both central elastic arteries and peripheral muscular arteries [54], which may be able to compensate for the loss of compliance due to aging [55]. Our study also found that the association of baPWV with K-MMSE score disappeared after adjusting for age. Therefore, baPWV was not associated with cognitive function, and may not be a good marker for age-related arterial stiffness, compared to ABI and cfPWV.

In addition, the non-significant association between baPWV and cognitive function may be partly due to the brief assessment of cognitive function. The K-MMSE lacks sensitivity to detecting early stage dementia or subtle changes in cognition [31]. Performance on the K-MMSE may also be affected by situational and psychological conditions, and it is best to interpret its scores in the context of other relevant test scores and subjects' histories. Similar to the current study's results, findings from the Baltimore Longitudinal Study of Aging [56], indicated that persons with higher baseline PWV tended to experience declines on tests of verbal learning and delayed recall, and nonverbal memory; however, PWV was not predictive of performance on the MMSE.

There are several limitations for the present study. First, to assess cognitive status, only the K-MMSE was employed in this study. Second, we did not consider the use of antihypertensives or statins. Some of these medications may reduce arterial stiffness, and associations with PWV might be attenuated by use of these medications. Another limitation is that using a visual rating scale and integrating PVHs and DWHs into WMHs might be less accurate than directly measuring the quantitative volume of WMHs. Lastly, the cross-sectional design provides limited evidence for causal inference. Although not validated in the present study, the method used in this study has been validated in the previous study [38]. Comparative study with other non-invasive assessments with validation [57] of arterial stiffness also should be considered in the future.

In this study, we measured the associations of $\mathrm{ABI}$ and baPWV with cognitive impairment and WMHs through a cross-sectional study. A lower $A B I$ value was an independent risk factor for cognitive impairment. Although a higher baPWV value was not, we are not able to completely rule out an association between increased PWV and risk of cognitive impairment due to a number of factors including the measurement site of PWV and use of the MMSE. However, a higher baPWV was associated with WMH severity. Further studies including both baPWV and cfPWV are needed to understand the exact roles in the cardiovascular system and brain function.

\section{Acknowledgment}

This study was performed by the financial support of the Catholic Medical Center Research Foundation made in the program year of 2012 and partly by a grant from the Korea Healthcare Technology R\&D project, Ministry of Health \& Welfare, Republic of Korea (HI10C2020). The authors thank Pamela E. May (Department of Psychology, Wayne State University) for consulting our research and English editing.

\section{References}

1. Gorelick PB, Scuteri A, Black SE, Decarli C, Greenberg SM, et al. (2011) Vascular contributions to cognitive impairment and dementia: a statement for healthcare professionals from the american heart association/american stroke association. Stroke 42: 2672-2713.
2. Guerchet M, Aboyans V, Nubukpo P, Lacroix P, Clément JP, et al. (2011) Ankle-brachial index as a marker of cognitive impairment and dementia in general population. A systematic review. Atherosclerosis 216: 251-257.

3. Hanon O, Haulon S, Lenoir H, Seux ML, Rigaud AS, et al. (2005) Relationship between arterial stiffness and cognitive function in elderly subjects with complaints of memory loss. Stroke 36: 2193-2197.

4. Hilal S, Saini M, Tan CS, Catindig JA, Dong YH, et al. (2014) Anklebrachial index, cognitive impairment and cerebrovascular disease in a chinese population. Neuroepidemiology 42: 131-138.

5. Price JF, McDowell S, Whiteman MC, Deary IJ, Stewart MC, et al. (2006) Ankle brachial index as a predictor of cognitive impairment in the general population: ten-year follow-up of the Edinburgh Artery Study. J Am Geriatr Soc 54: 763-769.

6. Sugawara N, Yasui-Furukori N, Umeda T, Kaneda A, Sato Y, et al. (2010) Comparison of ankle-brachial pressure index and pulse wave velocity as markers of cognitive function in a community-dwelling population. BMC Psychiatry 10: 46.

7. Caruana MF, Bradbury AW, Adam DJ. (2005) The validity, reliability, reproducibility and extended utility of ankle to brachial pressure index in current vascular surgical practice. European Journal of Vascular and Endovascular Surgery 29: 443-451.

8. Drouet L (2002) Atherothrombosis as a systemic disease. Cerebrovasc Dis 13 Suppl 1: 1-6.

9. Henry-Feugeas MC (2009) Intracranial MR dynamics in clinically diagnosed Alzheimer's disease: the emerging concept of "pulse wave encephalopathy". Curr Alzheimer Res 6: 488-502.

10. Brandts A, van Elderen SG, Westenberg JJ, van der Grond J, van Buchem MA, et al. (2009) Association of aortic arch pulse wave velocity with left ventricular mass and lacunar brain infarcts in hypertensive patients: assessment with MR imaging. Radiology 253: 681-688.

11. Hughes TM, Kuller LH, Barinas-Mitchell EJ, Mackey RH, McDade EM, et al. (2013) Pulse wave velocity is associated with $\hat{\mathrm{I}}^{2}$-amyloid deposition in the brains of very elderly adults. Neurology 81: 1711-1718.

12. King KS, Chen KX, Hulsey KM, McColl RW, Weiner MF, et al. (2013) White matter hyperintensities: use of aortic arch pulse wave velocity to predict volume independent of other cardiovascular risk factors. Radiology 267: 709-717.

13. Kuo HK, Chen CY, Liu HM, Yen CJ, Chang KJ, et al. (2010) Metabolic risks, white matter hyperintensities, and arterial stiffness in highfunctioning healthy adults. Int J Cardiol 143: 184-191.

14. Ohmine T, Miwa Y, Yao H, Yuzuriha T, Takashima Y, et al. (2008) Association between arterial stiffness and cerebral white matter lesions in community-dwelling elderly subjects. Hypertension Research 31: 75-81.

15. Rosano C, Watson N, Chang Y, Newman AB, Aizenstein HJ, et al. (2013) Aortic pulse wave velocity predicts focal white matter hyperintensities in a biracial cohort of older adults. Hypertension 61: 160-165.

16. Saji N, Kimura K, Shimizu H, Kita Y (2012) Association between silent brain infarct and arterial stiffness indicated by brachial-ankle pulse wave velocity. Intern Med 51: 1003-1008.

17. Saji N, Shimizu H, Kawarai T, Tadano M, Kita Y, et al. (2011) Increased brachial-ankle pulse wave velocity is independently associated with white matter hyperintensities. Neuroepidemiology 36: 252-257.

18. Tsao CW, Seshadri S, Beiser AS, Westwood AJ, Decarli C, et al. (2013) Relations of arterial stiffness and endothelial function to brain aging in the community. Neurology 81: 984-991.

19. Barber R, Scheltens P, Gholkar A, Ballard C, McKeith I, et al. (1999) White matter lesions on magnetic resonance imaging in dementia with Lewy bodies, Alzheimera"s ${ }^{\text {ms }}$ disease, vascular dementia, and normal aging. Journal of Neurology, Neurosurgery, and Psychiatry 67: 66-72.

20. Bots ML, van Swieten JC, Breteler MM, de Jong PT, van Gijn J, et al. (1993) Cerebral white matter lesions and atherosclerosis in the Rotterdam Study. Lancet 341: 1232-1237.

21. Debette S, Markus HS (2010) The clinical importance of white matter hyperintensities on brain magnetic resonance imaging: systematic review and meta-analysis. BMJ 341: c3666. 
Citation: Shim YS, Yoon B, Hong YJ, Cho AH, Shim DS, et al. (2014) Ankle-Brachial Pressure Index and Pulse Wave Velocity as Markers of White Matter Hyperintensities and Cognitive Impairment. J Neurol Neurophysiol 5: 239. doi:10.4172/2155-9562.1000239

Page 7 of 7

22. Ovbiagele B, Saver JL (2006) Cerebral white matter hyperintensities on MRI: Current concepts and therapeutic implications. Cerebrovasc Dis 22: 83-90.

23. Pantoni L, Garcia JH (1997) Pathogenesis of leukoaraiosis: a review. Stroke 28: 652-659.

24. Au R, Massaro JM, Wolf PA, Young ME, Beiser A, et al. (2006) Association of white matter hyperintensity volume with decreased cognitive functioning: the Framingham Heart Study. Arch Neurol 63: 246-250.

25. Provenzano FA, Muraskin J, Tosto G, Narkhede A, Wasserman BT, et al. (2013) White matter hyperintensities and cerebral amyloidosis: Necessary and sufficient for clinical expression of Alzheimer disease? JAMA Neurology 70: 455-461.

26. Henskens LH, Kroon AA, van Oostenbrugge RJ, Gronenschild EH, FussLejeune MM, et al. (2008) Increased aortic pulse wave velocity is associated with silent cerebral small-vessel disease in hypertensive patients. Hypertension 52: 1120-1126.

27. Mitchell GF (2008) Effects of central arterial aging on the structure and function of the peripheral vasculature: implications for end-organ damage. J Appl Physiol (1985) 105: 1652-1660.

28. Iadecola C, Park L, Capone C (2009) Threats to the mind: aging, amyloid, and hypertension. Stroke 40: S40-44

29. de Groot JC, de Leeuw FE, Oudkerk M, van Gijn J, Hofman A, et al. (2000) Cerebral white matter lesions and cognitive function: the Rotterdam Scan Study. Ann Neurol 47: 145-151.

30. van Oijen M, de Jong FJ, Witteman JC, Hofman A, Koudstaal PJ, et al. (2007) Atherosclerosis and risk for dementia. Ann Neurol 61: 403-410.

31. Kang Y, Na DL, Hahn S. (1997) A validity study on the Korean MiniMental State Examination (K-MMSE) in dementia patients. Journal of the Korean Neurological Association 15: 300-307.

32. Morris JC (1993) The Clinical Dementia Rating (CDR): current version and scoring rules. Neurology 43: 2412-2414.

33. Petersen RC (2004) Mild cognitive impairment as a diagnostic entity. J Intern Med 256: 183-194.

34. McKhann G, Drachman D, Folstein M, Katzman R, Price D, et al. (1984) Clinical diagnosis of Alzheimer's disease: report of the NINCDS-ADRDA Work Group under the auspices of Department of Health and Human Services Task Force on Alzheimer's Disease. Neurology 34: 939-944.

35. Shim YS, Youn YC, Na DL, Kim SY, Cheong HK, et al. (2011) Effects of medial temporal atrophy and white matter hyperintensities on the cognitive functions in patients with Alzheimer's disease. European Neurology 66: 75-82.

36. Fazekas F, Chawluk JB, Alavi A, Hurtig HI, Zimmerman RA (1987) MR signal abnormalities at $1.5 \mathrm{~T}$ in Alzheimer's dementia and normal aging. AJR Am J Roentgenol 149: 351-356.

37. Niazi K, Khan TH, Easley KA (2006) Diagnostic utility of the two methods of ankle brachial index in the detection of peripheral arterial disease of lower extremities. Catheter Cardiovasc Interv 68: 788-792.

38. Yamashina A, Tomiyama H, Takeda K, Tsuda H, Arai T, et al. (2002) Validity, reproducibility, and clinical significance of noninvasive brachial-ankle pulse wave velocity measurement. Hypertension Research 25: 359-364.

39. Folstein MF, Folstein SE, McHugh PR (1975) "Mini-mental state". A practical method for grading the cognitive state of patients for the clinician". Journal of Psychiatric Research 12: 189-198.
40. Hughes CP, Berg L, Danziger WL, Coben LA, Martin RL (1982) A new clinical scale for the staging of dementia. Br J Psychiatry 140: 566-572.

41. Hachinski VC, Iliff LD, Zilhka E, Du Boulay GH, McAllister VL, et al. (1975) Cerebral blood flow in dementia. Arch Neurol 32: 632-637.

42. Grasel E, Cameron S, Lehrl S. (1990) What contribution can the Hachinski Ischemic Scale make to the differential diagnosis between multi-infarct dementia and primary degenerative dementia? Archives of Gerontology and Geriatrics 11: 63-75.

43. Laurin D, Masaki KH, White LR, Launer LJ (2007) Ankle-to-brachial index and dementia: the Honolulu-Asia Aging Study. Circulation 116: 2269-2274.

44. Elias MF, Robbins MA, Budge MM, Abhayaratna WP, Dore GA, et al. (2009) Arterial pulse wave velocity and cognition with advancing age. Hypertension 53: 668-673.

45. Johnson TE (2006) Recent results: biomarkers of aging. Exp Gerontol 41: 1243-1246.

46. Poels MM, van Oijen M, Mattace-Raso FU, Hofman A, Koudstaal PJ, et al. (2007) Arterial stiffness, cognitive decline, and risk of dementia: the Rotterdam study. Stroke 38: 888-892.

47. Singer J, Trollor JN, Crawford J, O'Rourke MF, Baune BT, et al. (2013) The association between pulse wave velocity and cognitive function: the Sydney Memory and Ageing Study. PLoS One 8: e61855.

48. Zhong W, Cruickshanks KJ, Schubert CR, Carlsson CM, Chappell RJ, et al. (2014) Pulse wave velocity and cognitive function in older adults. Alzheimer Dis Assoc Disord 28: 44-49.

49. Fukuhara M, Matsumura K, Ansai T, Takata Y, Sonoki K, et al. (2006) Prediction of cognitive function by arterial stiffness in the very elderly. Circ J 70: 756-761.

50. Scuteri A, Brancati AM, Gianni W, Assisi A, Volpe M (2005) Arterial stiffness is an independent risk factor for cognitive impairment in the elderly: a pilot study. J Hypertens 23: 1211-1216.

51. Zeki Al Hazzouri A, Newman AB, Simonsick E, Sink KM, Sutton Tyrrell $\mathrm{K}$, et al. (2013) Pulse wave velocity and cognitive decline in elders: the Health, Aging, and Body Composition study. Stroke 44: 388-393.

52. Sugawara J, Hayashi K, Yokoi T, Cortez-Cooper MY, DeVan AE, et al. (2005) Brachial-ankle pulse wave velocity: an index of central arterial stiffness? J Hum Hypertens 19: 401-406.

53. Choi JC, Lee JS, Kang SY, Kang JH, Bae JM, et al. (2009) Limitation of brachial-ankle pulse wave velocity in assessing the risk of stroke: importance of instantaneous blood pressure. Cerebrovasc Dis 27: 417-425.

54. Yu WC, Chuang SY, Lin YP, Chen CH (2008) Brachial-ankle vs carotidfemoral pulse wave velocity as a determinant of cardiovascular structure and function. J Hum Hypertens 22: 24-31.

55. Van Bortel L (2002) Focus on small artery stiffness. J Hypertens 20: 1707-1709.

56. Waldstein SR, Rice SC, Thayer JF, Najjar SS, Scuteri A, et al. (2008) Pulse pressure and pulse wave velocity are related to cognitive decline in the Baltimore Longitudinal Study of Aging. Hypertension 51: 99-104.

57. Horvath IG, Nameth A, Lenkey Z, Alessandri N, Tufano F, et al. (2010). Invasive validation of a new oscillometric device (Arteriograph) for measuring augmentation index, central blood pressure and aortic pulse wave velocity. J Hypertens 28: 2068-2075. 